\title{
Da Escola Isolada Mista da Vila do Espírito Santo do Curipi à escola diferenciada entre os Karipuna: entrelaçamentos na história da educação escolar indígena
}

\author{
From the isolated mixed school of Vila do Espírito Santo do \\ Curipi to the differentiated school among the Karipuna: \\ intersections in the history of the indigenous school education
}

Edson Machado de Brito*

\section{Resumo}

O presente texto, baseado na minha tese de doutorado, apresenta a educação karipuna do Amapá no contexto da educação escolar indígena diferenciada na Aldeia Espírito Santo, no processo de implantação e funcionamento da Escola Isolada Mista da Vila do Espírito Santo do Curipi, situada na Terra Indígena do povo Karipuna, na região do Oiapoque, na década de 1930. O tema se entrelaça com a história da educação escolar indígena no Brasil, pontuando as mudanças ocorridas a partir dos anos 1980, principalmente em decorrência das conquistas constitucionais e da legislação subsequente, que aponta possibilidades para uma educação escolar diferenciada. Palavras-chave: história da educação escolar indígena; história da educação; educação indígena; Karipuna.

\begin{abstract}
This text, produced based on doctoral dissertation, presents Amapa's Karipuna education in the context of the differentiated indigenous school education in Espírito Santo Village, in its process of introduction and running of the Mixed Isolated School of Espírito Santo of Curipi Village, located in Karipuna's Indigenous Reservation, in the region of Oiapoque river, in the 1930s. This subject intersects with the history of indigenous school education in Brazil, showing the changes which began in the 1980s, mainly due to constitutional achievements and its subsequent legislation, pointing out possibilities for a differentiated indigenous school education.

Keywords: history of indigenous school education; history of education; indigenous education; Karipuna.
\end{abstract}

*Coordenador da Licenciatura Intercultural Indígena e professor de História Indígena no Instituto Federal de Educação e Tecnologia da Bahia - Campus Porto Seguro. BR 367, km 57,5 - Fontana I. 45810-000 Porto Seguro - BA - Brasil. edson@ifba.edu.br 


\section{A Escola da Vila do Espírito Santo do Curipi}

A escola faz parte da realidade dos Karipuna da aldeia do Espírito Santo desde a década de 1930, quando o Estado brasileiro decidiu pela ocupação efetiva da fronteira nacional na região do Oiapoque, no atual estado do Amapá, tendo como guardiões da fronteira os povos indígenas, os quais deveriam ser 'abrasileirados' para o cumprimento de tal tarefa. A escola fundada na aldeia do Espírito Santo no dia 1o de fevereiro de 1934, denominada Escola Isolada Mista da Vila do Espírito Santo do Curipi, por iniciativa do governo do estado do Pará, iniciou a sua atividade com 57 alunos e funcionou até 1937, como demonstra Arnaud. ${ }^{1}$ A Escola trataria não apenas do 'abrasileiramento' dos Karipuna, mas também de sua 'elevação aos níveis da civilidade e do progresso', por intermédio da transmissão de valores novos, que promovessem o patriotismo, o civismo, a higiene e a preparação para o mundo do trabalho produtivo.

O contexto em que a escola foi criada interliga aspectos políticos e sociais do plano local ao plano nacional. No plano local havia a preocupação com a efetiva ocupação da fronteira nacional e a formação dos indígenas para serem os guardiões da fronteira territorial, o que incluía a formação patriótica, cívica e para o trabalho, e do ponto de vista nacional estava em andamento o plano de educação voltado para o progresso da nação. A escola era uma novidade na aldeia, iniciando uma interferência que se desdobraria no estabelecimento de uma tensa relação com a comunidade local.

Partindo da constatação de que ela remonta à década de 1930, é possível observar aspectos que fazem lembrar o projeto escolar em andamento no país no período em questão, estabelecendo semelhanças da escola indígena com a escola não indígena, reportando tais semelhanças ao conceito de forma escolar, segundo o qual:

se caracteriza por um conjunto coerente de traços - entre eles, deve-se citar, em primeiro lugar, a constituição de um universo separado para a infância; a importância das regras na aprendizagem; a organização racional do tempo; a multiplicação e a repetição de exercícios, cuja única função constitui em aprender e aprender conforme as regras ou, dito de outro modo, tendo por fim seu próprio fim. ${ }^{2}$ 
Carvalho (2003) apresenta concepção semelhante, segundo a qual a forma escolar envolve "a organização espacial, o lugar do professor, a disposição dos alunos, o movimento dos grupos na classe e no pátio; a organização temporal, o emprego dos dias, das horas e mesmo dos minutos de aula; a repartição disso que chamamos tão justamente de disciplinas". ${ }^{3}$ É possível verificar na recém-fundada Escola do Curipi aspectos que estão presentes nas escolas convencionais projetadas durante o governo Getúlio Vargas no país. Estão presentes os ideais homogeneizadores e disciplinadores próprios da época em questão. Nela, as crianças passaram por um processo de uniformização tanto nas formas de vestir como em uma ordem que transpirava a disciplinaridade e a ordem, integrando a escola da aldeia ao ideal da 'regeneração' e 'superação do atraso'.

No contexto nacional, é importante destacar que na década de 1930 estava em marcha no país um projeto educacional que defendia a ideia de 'transformar a sociedade pela educação', tirando o Brasil do atraso agrário/rural para colocá-lo no caminho do progresso. A proposta se apresentava como 'regeneradora das populações brasileiras' e racionalizadora do mundo do trabalho, combatendo a 'amorfia social', por uma 'reforma dos costumes'. A reforma do sistema do ensino brasileiro, orientada pelos pressupostos da 'pedagogia nova', tinha caráter homogeneizador e conformador da sociedade, pautando os seus procedimentos na disciplina e na ideia de regrar a liberdade, visando à construção de 'uma nova civilização'. A prática regionalista da velha oligarquia brasileira foi paulatinamente substituída pelo projeto de padronização do ensino e de centralização das atividades escolares, pela defesa da unidade de programas, de material didático, de normas e diretrizes educacionais. ${ }^{4}$

Apesar dos embates entre os grupos políticos divergentes, o modelo de educação que se instaurou após 1930 no país foi a expressão e manifestação do novo padrão econômico e social que se instalava naquela época. O projeto de Estado Nacional, de centralização e integração política e econômica, tinha a educação como base para instituir-se, visando formar física e mentalmente o 'novo homem' propagado pelo Estado. A escola tinha como função 'normatizar' as pessoas primando por uma sociedade civilizada e ordeira, por meio de uma educação que conformasse as pessoas aos princípios defendidos pelo Estado (Carvalho, 2003). 
Além de estar inserida nesse contexto político-educacional, a criação da Escola da Vila do Espírito Santo está contextualizada em outro aspecto relevante: a questão da fronteira internacional com a Guiana Francesa. Desde o século XVII o norte do Amapá foi alvo de disputas, no primeiro momento envolvendo a Coroa portuguesa e a França e, após 1822, envolvendo o Estado brasileiro e a França. Tensões e confrontos bélicos frequentes entre amapaenses e franceses na região foram encerrados com a celebração do Tratado de Berna (pactuado entre o Brasil e a França), assinado em dezembro de 1900, definindo o rio Oiapoque como o limite da fronteira entre o Brasil e a Guiana Francesa. Ricardo ${ }^{5}$ esclarece que foi especialmente no contexto pós-Tratado de Berna que o Estado brasileiro se voltou para a formulação e execução do projeto de nacionalizar a fronteira brasileira no Oiapoque e abrasileirar os povos indígenas da região para torná-los guardiões da fronteira.

Expedito Arnaud (1989) demonstra que após a expedição oficial ao Oiapoque comandada na década de 1920 pelo então general Cândido Rondon, o Estado brasileiro decidiu pelo minucioso controle da população indígena local, visando transformá-los em efetivos cidadãos brasileiros e guardiões da fronteira com a Guiana Francesa. Para atingir tais objetivos, a escola foi uma das instituições de maior alcance, pois nela os Karipuna aprenderam a língua portuguesa, abandonando a língua utilizada até então, o patuá. No entanto, a ação da escola não se restringiu à obrigatoriedade da língua portuguesa; ao mesmo tempo foi imposta a proibição dos rituais próprios daquela cultura e a introdução dos ritos cívicos e hábitos próprios da sociedade brasileira. Os agentes escolares penalizavam com castigos corporais os indígenas que insistissem em manter os seus hábitos e as tradições originárias.

Nesse contexto de nacionalização da fronteira, os Karipuna foram diretamente atingidos pelo Estado brasileiro. O relato de Rondon é esclarecedor:

Assim foi o grande etnólogo Curt Nimuendajú encontra-los, em 1925, com uma população de mais ou menos 150 almas; nesse estado encontrei-os também, em 1931, contando a essa altura 196 pessoas.

População ordeira, boa e trabalhadora, fabricando já $60 \%$ da farinha produzida na região, são de suas plantações as saborosas laranjas e tangerinas que vem ao Oiapoque.

Em 1934, o Cel. Magalhães Barata, então interventor federal do Pará, entre as incontáveis escolas que criou no estado, criou também 3 entre os índios Galibir, 
Pariucur e Caripuna, sendo que esta última, pelo grau de adiantamento em que se achavam os índios, deu ótimos resultados. Este é o motivo por que, entre os Caripuna, existem alguns que leem e escrevem, embora pouco.

A ação do Serviço de Proteção aos Índios tem sido benéfica e a ela muito se deve o progresso econômico e cultural dessa gente, que faz questão de ser índia e que ainda conserva muitas das suas tradições e costumes. ${ }^{6}$

Fica evidente que o Estado brasileiro passou a intervir sistematicamente na vida dos Karipuna. A escola fundada entre eles, em 1934, à qual Rondon se reporta, foi instalada no bojo do projeto de nacionalização daquela fronteira. Eneida Assis ${ }^{7}$ conclui que a escola instalada na Vila do Espírito Santo funcionava como um 'centro de controle' que visava integrar os Karipuna à comunhão nacional, colaborando com a fixação deles em território brasileiro, uma vez que frequentemente os Karipuna conviviam dispersos nas cidades da Guiana Francesa e na região do Oiapoque. Paralelamente, o Serviço de Proteção aos Índios (SPI) estimulou o desenvolvimento e a diversificação das atividades produtivas entre os Karipuna, mediando a comercialização entre indígenas e não índios, evitando que os primeiros fossem explorados (Arnaud, 1989, p.19).

Sobre a escola entre os Karipuna, Arnaud (1989) informa que à época da sua fundação, em 1934, havia 57 alunos, e que entre outras atividades pedagógicas as crianças cantavam diariamente o Hino Nacional e tinham aulas de civismo. Tassinari afirma que "a escola que funcionava no Curipi, inicialmente na aldeia do Espírito Santo e logo transferida para Santa Isabel, tinha sinais cotidianos de ordem, respeito às autoridades e aos símbolos nacionais", assim como informa sobre os "antigos métodos da palmatória e da proibição do uso do patois na sala de aula". ${ }^{8}$

Arnaud $^{9}$ esclarece que a escola fundada entre os Karipuna, assim como as demais escolas criadas no Uaçá, em 1934, tiveram duração curta, tendo encerrado as atividades em 1937. No entanto, Rondon observa que a escola entre os Karipuna deu ótimo resultado, "pelo grau de adiantamento em que se achavam” aqueles indígenas (Rondon, 1953, p.282).

Dona Acelina Forte, Kariouna de 75 anos, em entrevista concedida em 2008, informou que foi aluna da primeira escola fundada na aldeia, em 1934. Narrando as suas memórias do tempo de aluna, ela descreve que:

Naquele tempo era bom. Não era igual hoje que os pequenozinho ficam solto por 
aí. Tinha que estudar, saber os números, tinha que ler. A professora Verônica era pessoa boa, mas ela era braba. Ela tinha uma régua de pau que batia na mão de quem não aprendesse o que ela ensinava. Eu estudei a terceira série com ela e levei muitas palmadas para aprender.

O depoimento de dona Acelina deve ser considerado sob duas perspectivas, pelo menos: em primeiro plano deve-se considerar que a professora Verônica atuou por várias décadas na região do Uaçá, o que abre a possibilidade de dona Acelina ter sido efetivamente aluna de dona Verônica em algum tempo. De outro ponto de vista, deve-se pensar a memória como uma construção dinâmica que se atualiza nas relações sociais e no tempo. Como se verá adiante, em diversas entrevistas os depoentes convergem no sentido de elogiar a professora Verônica, fato que pode ter colaborado na construção da memória de dona Acelina.

Outro depoimento, complementar, foi concedido em julho de 2009 pelo senhor Manuel dos Santos, de 88 anos, que não soube identificar com precisão o tempo cronológico dos fatos que narrou, mas forneceu inúmeras informações significativas sobre a escola na aldeia do Espírito Santo nos anos iniciais de funcionamento. Diz ele:

Não lembro quanto tempo estudei, mas lembro que só tinha até a $5^{\mathrm{a}}$ série, depois não tinha mais nada pra estudar. A escola não era lá em cima onde é hoje, ela era em outro lugar. A dona Verônica ensinava de tudo, ela era muito inteligente, ela ensinava matemática, português e outras coisas. Era a Funai que trazia ela pra cá e ela batia com uma palmatória, batia na mesa, na mão da gente, mas ao menos a gente aprendia. As coisas dos índios não podia fazer na escola, ela não deixava. Foi bom que aprendemos a língua dos brasileiros.

A professora foi contratada pelo governo do estado do Pará e depois pelo SPI para vir trabalhar na região do Curipi - e não pela Funai, como expressou o senhor Manuel Santos -, pois conforme Tassinari, a professora atuou no Curipi “por quase trinta anos" (2003, p.357), portanto, não exerceu a docência durante a ditadura militar, quando foi criada a Funai, uma vez que ela chegou à região na década de 1920 .

De toda forma, as narrativas dos entrevistados evidenciam a implantação de um modelo de educação escolar pautado em práticas conservadoras que, 
no entanto, não foram recebidas com animosidade, pois todos mostraram simpatia pela professora. Segundo Tassinari (2003), a professora Verônica tinha grande aceitação entre os Karipuna, sendo até reconhecida como 'nossa parente' por eles. Ela chegou ao Curipi em 1924, sendo originária da região de Vigia, estado do Pará, e aceita pela comunidade, segundo afirma Tassinari: "Não conheci um Karipuna que não tenha elogios para a professora Verônica, mesmo da parte de ex-alunos, elogios dos antigos métodos da palmatória e da proibição do uso do patois na sala de aula" (2003, p.361). Em nome da escola, a professora determinou ainda a proibição das práticas xamânicas, sob pena de severos castigos corporais, como atestam os próprios depoentes.

De fato, contraditoriamente, os mais velhos falam das proibições e entendem claramente que a escola implantada na aldeia interferiu na organização social da comunidade, mas afirmam o tempo todo que aquilo foi positivo no aprendizado de novos conhecimentos, necessários à realidade local, uma vez que os Karipuna mantêm relações comerciais e políticas com o entorno, desde o século XIX.

No entanto, mais importante do que a constatação do vínculo institucional da professora Verônica é a análise das suas ações pedagógicas e dos desdobramentos da sua presença na aldeia do Espírito Santo por décadas. Por mais que dona Verônica tivesse a confiança dos Karipuna e fosse considerada por eles como uma 'pessoa inteligente', a realidade é que ela esteve à frente do projeto de educar para 'abrasileirar', uma política educacional que, no limite, se assemelha ao projeto jesuítico nos meios indígenas à época colonial, resguardando as devidas diferenças. Assis (1981) explica que as professoras que atuavam na região do Curipi tinham o poder de decisão administrativa e curricular nas escolas, e na escola da aldeia do Espírito Santo dona Verônica estabeleceu a obrigatoriedade de todos falarem a língua portuguesa, não apenas na escola, mas em toda a aldeia.

Além das evidências expressas nos depoimentos dos velhos Karipuna da aldeia do Espírito Santo, a bibliografia sobre a temática evidencia a extensão da influência da professora Verônica no meio Karipuna. Tassinari (2003) esclarece que "a escola, no Curipi, não pode ser entendida como uma instituição externa e alheia às vontades dos grupos, mas foi incorporada, na professora Verônica, como parente, como parte da família" (p.359). Nessa perspectiva, a escola naquela aldeia assume uma contradição, pois as práticas pedagógicas 
desestruturadoras das tradições locais passaram a ser vistas com bons olhos por grande parte dos Karipuna. Tassinari observa que a professora Verônica era uma profissional carismática, criativa, sensível e enérgica. Daí, a autora faz a seguinte inferência:

Logo, pode-se entender a aceitação por parte das famílias da maioria das regras e imposições trazidas pela escola não apenas como uma relação de 'opressão' entre governo/SPI e as famílias indígenas, sendo estas últimas o polo passivo da relação. Pelo contrário, houve engajamento ativo das famílias no projeto de escola e mesmo as políticas de 'abrasileiramento' foram vistas como alternativas para 'melhorar', 'progredir'. (2003, p.360)

Além dos argumentos já apresentados, é importante considerar que a região do Curipi é de difícil acesso, distante dos centros urbanos e dos órgãos de decisão. Ainda hoje os professores são muito respeitados entre os indígenas, sejam professores indígenas ou não índios. Esses esclarecimentos elucidam a força política que a professora Verônica exercia sobre os Karipuna durante as décadas de 1920, 1930 e 1940. Mas é evidente que em última instância o poder da professora emanava do Estado, assim como as regras e metodologias pedagógicas utilizadas nas escolas das aldeias. O Estado brasileiro declarava que o seu projeto entre os Karipuna pretendia 'abrasileirar', fazer 'progredir' e 'superar o atraso pelo trabalho produtivo', implantando 'novos modos de vida'.

Assis (1981) considera que as ações pedagógicas utilizadas por dona Verônica contribuíram de forma decisiva para que a comunidade Karipuna na aldeia do Espírito Santo deixasse de ensinar o patuá para as crianças, fato que levou não apenas ao abalo das tradições Karipuna como um todo, mas também ao quase total abandono da língua nativa durante décadas.

Apesar do curto funcionamento na sua primeira fase, até 1937, a escola entre os Karipuna, na avaliação do governo do estado do Pará e do SPI, tinha apresentado ótimos resultados, demonstrados no fato de que alguns daqueles indígenas 'aprenderam a ler e escrever' (Rondon, 1953, p.282). Provavelmente a escola não teve continuidade por falta de recursos financeiros e apoio técnico, pois apesar da presença do SPI na região, a sua 'atuação ocorre de modo superficial' nessa fase. Por intermédio de um Delegado, limitou-se a intermediar as transações comerciais dos povos indígenas com os não índios, não tendo a instituição assumido efetivamente a educação escolar na região. 
Portanto, as atividades das escolas da região do Uaçá, particularmente entre os Karipuna, foram suspensas entre os anos de 1937 e 1948, período que coincide com a implantação do Estado Novo, a Segunda Guerra Mundial e a criação do Território Federal do Amapá. Ressalta-se que o projeto educacional implantado na Escola do Curipi e seus desdobramentos nos anos seguintes são pautados por parâmetros nacionais, ou seja, o civismo, a educação física e o incentivo aos trabalhos manuais são aspectos comuns em todas as escolas durante o governo Vargas, independentemente de serem indígenas ou não. Portanto, qualquer tipo de opressão era igualmente comum a todos.

No entanto, considerando a história dos povos indígenas, é importante voltar os olhos para a particularidade Karipuna da aldeia do Espírito Santo, destacando dois aspectos relevantes para análise em termos da presença da escola: primeiro, trata-se de um povo indígena, com língua e tradições particulares, portanto, diversas do restante da comunidade nacional; segundo, trata-se de um povo situado numa região de permanentes conflitos de limites territoriais, nos quais o Estado nacional decidiu intervir por intermédio da escola.

Seguindo as análises sobre a atuação da escola na região do Uaçá, Arnaud (1984) afirma que a partir de 1942 o SPI se tornou mais atuante na localidade, assumindo a responsabilidade pela escola entre os indígenas, tendo estado ela anteriormente sob responsabilidade do governo do estado do Pará. O autor descreve algumas atividades desenvolvidas pelo órgão junto aos povos indígenas:

criou uma ajudância na Vila do Espírito Santo (hoje cidade do Oiapoque) e instalou um posto de nacionalização na confluência do Uaçá com o Curipi (Incruso), passando desde então a aplicar uma série de planos tendo em vista o desenvolvimento da lavoura e da pesca, o estabelecimento da pecuária e de indústrias, a criação de um entreposto comercial para transacionar com os índios, e a prestação de assistência sanitária e escolar. (Arnaud, 1984, p.21)

O SPI criou em 1948 uma escola entre os Karipuna, na localidade em que hoje está a aldeia de Santa Isabel (em frente à aldeia do Espírito Santo, do outro lado do rio), reintroduzindo a escola na localidade. Arnaud afirma que desde então a escola manteve uma média de 75 alunos, de 7 a 17 anos, e que a sua estrutura curricular seguia o roteiro do Território Federal do Amapá, incluindo 
"o ensino de orações cristãs, hinos patrióticos e das festas cívicas nacionais" (1989, p.103). Tal proposta curricular estava pautada na 'pedagogia da nacionalidade e do civismo', prevista no Regulamento do SPI, aprovado pelo Decreto 736, de 6 de abril de 1936. O autor acrescenta que esses ensinamentos "foram ampliados através do aprendizado de costura à máquina para as meninas e do plantio de hortas para ambos os sexos" (ibidem, p.103).

Seu Manoel dos Santos, em entrevista concedida em julho de 2009, lembrou-se da escola que funcionou na aldeia de Santa Isabel: "Lá os meninos tinha aula de horta e de artesanato, as mulheres também iam pra horta, mas aprendia a cozinhar, costurar e fazer outras coisas de mulher ... Todo dia eles cantavam o hino nacional e marchavam pela aldeia". Portanto, verifica-se que além das influências da política nacional para a educação brasileira, as escolas indígenas na região do Uaçá estavam submetidas a outros aspectos e interesses, entre eles, as políticas indigenistas do SPI e as ações do Estado para a segurança nacional em território de fronteira internacional. Obviamente, todas essas ações ocorriam de forma integrada, e não isoladamente.

Arnaud ressalta que a partir da década de 1950 a representação do SPI local sofreu um drástico corte em seus recursos financeiros, pois o SPI nacional decidiu concentrar os recursos da Instituição na resolução de conflitos abertos no sul do Pará, entre indígenas e seringueiros, o que provocou o desdobramento de dois problemas imediatos na região do Uaçá: a precarização salarial dos servidores e a sua constante rotatividade, uma vez que pediam dispensa em razão dos baixos salários, mesmo os professores. Segundo o autor, as iniciativas para a resolução dos problemas por parte do administrador local do SPI não foram bem sucedidas, mas de toda forma Arnaud afirma que "no setor escolar, os trabalhos não sofreram interrupção, havendo a frequência nas duas escolas se mantido com médias idênticas às da fase anterior (75 alunos)" (1989, p.107). As duas escolas às quais Arnaud se reporta são a escola Karipuna de Santa Isabel e a escola do povo Galibi.

A partir de 1964, as escolas indígenas do Uaçá passaram a contar com professores contratados pelo governo do Território Federal do Amapá, mediante convênio firmado com o SPI visando resolver o problema da carência de profissionais. No entanto, a rotatividade desses profissionais continuou em razão de sua pouca experiência junto às comunidades indígenas (Arnaud, 1989). Os professores ficavam algum tempo na aldeia e desistiam por causa do 
isolamento e das diferentes formas de vivência na localidade, típicas dos povos do Uaçá, fato que pode ser entendido como um indício em dois sentidos: em primeiro plano o Estado mantinha abertamente a política da 'assimilação' dos povos da região, pela manutenção da escola e de professores que não conheciam e nem respeitavam as diversidades sociolinguísticas; num outro plano, observa-se o caráter reativo e a potência dos povos indígenas e dos Karipuna, em especial, que mantinham suas fronteiras identitárias a ponto de amedrontar os 'forasteiros' ou 'brasileiros', como eles mesmos denominam. Fica evidente que o antigo projeto de extinguir as diferenças mediante a 'assimilação dos povos indígenas à comunhão nacional' nunca foi uma tarefa simples ou sem resistência por parte desses povos.

A respeito da situação das escolas no Uaçá, Ricardo (1983) se posiciona de maneira diferente da proposição de Arnaud: verifica que entre 1950 e 1967 as escolas na região do Uaçá funcionaram de forma precária e irregular. A partir do final da década de 1960, com a presença da Funai na região em parceria com o governo do Território Federal do Amapá, a escola entre os Karipuna passou a contar com mais recursos e contratação de pessoal. A partir de 1970 a Funai oficializou, por convênios, a transferência definitiva da educação escolar indígena no Amapá para o governo do Território, que através da sua Secretaria de Educação assumiu toda a estrutura educacional das escolas das aldeias, até mesmo a definição curricular para as escolas Karipuna, mas sem considerar a especificidade indígena, como lembra Assis (1981).

Segundo Tassinari, ${ }^{10}$ em 1976 foi criada uma nova escola na aldeia do Espírito Santo, a qual viria a se chamar posteriormente de Escola Estadual João Teodoro Forte. A partir de 1978 as escolas indígenas do Amapá adotaram o novo programa curricular para as escolas de zona rural de $1^{\underline{a}}$ a $4^{\underline{a}}$ séries, o qual incluía Comunicação e Expressão (Português), Matemática, Ciências, Integração Social e Estudos Sociais.

Ricardo (1983) diz que o entrosamento da Funai com o governo do Território Federal do Amapá se deu apenas a partir da década de 1980, tendo como parceiro a Secretaria de Educação do Município do Oiapoque, introduzindo os Projetos Mobral e Casulo nas escolas indígenas.

Diante do exposto, é possível perceber as ambiguidades da escola implantada entre os Karipuna, em 1934, e seus desdobramentos nas décadas seguintes. A perspectiva crítica fundada na proposta da educação escolar indígena 
diferenciada, que busca fortalecer e valorizar as tradições indígenas no diálogo intercultural, concebe que a escola fundada na aldeia do Espírito Santo e as suas ações pedagógicas prolongadas até a final da década de 1980 foram desarticuladoras das formas tradicionais de organização desse povo, negando os princípios da educação propriamente Karipuna. O funcionamento daquela escola com os seus mecanismos punitivos, a separação entre meninos e meninas em espaços diferentes e a obrigatoriedade em falar o português, entre outros aspectos, explicitam a imposição de um modelo educacional de homogeneização cultural e etnocêntrico.

\section{Educação Escolar Indígena Diferenciada}

A educação escolar indígena diferenciada é um projeto em construção na sociedade brasileira. Conforme demonstra Dias da Silva (1997), a proposta é necessária, pois:

Como se sabe, ao longo da história, temos exemplos que evidenciam os resultados desastrosos que distintos programas de 'educação para índios' acarretaram para as populações indígenas ... Penso que é preciso ir além do 'respeito ao outro'. $\mathrm{O}$ respeito entre as culturas, o 'dar lugar e espaço às diferenças', é um passo - decisivo - mas que não esgota o delicado processo de construção de uma sociedade plural. $^{11}$

A autora concebe a educação escolar indígena diferenciada como um instrumento "que pode vir a ser algo que contribua para a vida dos povos indígenas (operando não sem riscos e contradições) apesar de sua história e objetivos integracionistas" (ibidem, p.64).

Atualmente o Estado brasileiro e as agências promotoras da educação escolar indígena defendem um modelo de escola indígena diferenciada que fortaleça e valorize as tradições desses povos, tendo o bilinguismo, a interculturalidade e a especificidade como bases fundamentais da escola. No entanto, há uma tensão entre o discurso declarado e as práticas efetivas, pois quase sempre o que a lei estabelece não é respeitado pelo poder público.

A educação escolar indígena diferenciada pode ser inicialmente definida como a busca da alternativa à educação escolar indígena de viés colonizador. 
Gersem Luciano ${ }^{12}$ concebe a educação escolar indígena diferenciada como um instrumento de respeito aos complexos sistemas de pensamentos e modos de produzir e de organização social que os povos indígenas criam e reelaboram ao longo do tempo. Tais conhecimentos devem ser potencializados com o diálogo com os demais conhecimentos não indígenas. O entendimento de Luciano converge com a sugestão de Mindlin (1994), que defende a proposta de que:

O ponto de partida para todo o conteúdo a ser ensinado aos índios é a cultura indígena - valorizar o que são, fazer deles pesquisadores do próprio mundo e do saber dos mais velhos, extrair os fios antigos de um conhecimento e formas de vida que estão sendo abandonados. ${ }^{13}$

Os autores citados apontam caminhos inovadores e diferentes das políticas públicas que o Estado projetou para os povos indígenas até o final do século passado, quando teve início o movimento pela educação escolar indígena diferenciada.

Os debates em torno da escola que atenda aos interesses dos povos indígenas e que valorize os seus conhecimentos está em pauta desde o final da década de 1970, sendo tema de debate tanto pelo poder público como pelo movimento indígena, em colaboração com as organizações indigenistas. A partir da década de 1970, a população indígena brasileira iniciou o processo de reorganização, avançando significativamente na conquista de espaços sociais e políticos. Ângelo (2002) considera que as mobilizações e organizações dos povos indígenas, com o apoio dos setores democráticos do país, iniciaram um movimento sistemático para contrariar as ações do Estado brasileiro em termos do projeto integracionista. Paulatinamente o movimento indígena foi se fortalecendo e organizando as suas lutas em busca da autodeterminação e da conquista da cidadania, iniciando timidamente o debate em torno da escola demandada pelos próprios povos indígenas.

A partir da década de 1980, os movimentos em torno da Constituinte indicavam novos rumos para a política indigenista no Brasil. A Constituição promulgada em 1988 definia nos artigos 210, 215 e 231 os parâmetros que a educação escolar indígena deveria seguir. Abria-se formalmente a possibilidade da educação escolar indígena diferenciada, com objetivos e formas de funcionamento específicos, diferentes das escolas não indígenas. A proposta da educação escolar indígena diferenciada prioriza o ensino na língua originária, 
respeitando a especificidade de cada povo, o que significa dizer que não há um formato unitário de educação escolar indígena diferenciado para todos os povos, daí o seu caráter específico e comunitário.

A partir da Constituição Federal de 1988 a educação escolar indígena passou a receber um tratamento diferenciado por parte do Ministério da Educação, ou melhor, o Decreto 26/1991 transferiu a responsabilidade pela educação escolar indígena da Funai para o Ministério da Educação (MEC). Dessa maneira o MEC assumiu a coordenação das ações educacionais junto aos povos indígenas no país, em parceria com as secretarias estaduais e municipais de educação e instituições de ensino superior, tanto em termos de financiamento e cooperação técnica, quanto em relação à definição de diretrizes curriculares, estabelecendo a necessidade do diálogo franco e participativo com as comunidades indígenas nas definições curriculares. Faz parte das políticas de educação escolar indígena diferenciada a criação de programas de formação específica para professores indígenas e de publicação de materiais didáticos diferenciados, além da elaboração de programas específicos para o atendimento das necessidades das escolas indígenas.

A Portaria Interministerial 559/1991 deliberou sobre a criação da Coordenação Nacional da Educação Escolar Indígena e dos Núcleos de Educação Escolar Indígena no âmbito das Secretarias Estaduais de Educação, com representação de entidades indígenas, bem como estabeleceu as orientações gerais da educação escolar indígena diferenciada, intercultural, bilíngue e específica. Dois anos depois, o MEC publicou o Referencial Curricular Nacional para as Escolas Indígenas (RCNEI), ${ }^{14}$ objetivando oferecer subsídios para a formulação de planos de aulas e projetos pedagógicos para as escolas indígenas.

Os avanços legais direcionados à educação escolar indígena diferenciada prosseguiram com a aprovação da Lei de Diretrizes e Bases da Educação Brasileira (LDB), Lei 9.394/1996. ${ }^{15}$ O parágrafo terceiro do artigo 32 "assegura às comunidades indígenas a utilização de suas línguas maternas e processos próprios de aprendizagem", e os artigos 78 e 79 estabelecem que:

Art. 78. O Sistema de Ensino da União, com a colaboração das agências federais de fomento à cultura e de assistência aos índios, desenvolverá programas integrados de ensino e pesquisa, para oferta de educação escolar bilíngue e intercultural aos povos indígenas, com os seguintes objetivos: 
I - proporcionar aos índios, suas comunidades e povos, a recuperação de suas memórias históricas; a reafirmação de suas identidades étnicas, a valorização de suas línguas e ciências;

II - garantir aos índios, suas comunidades e povos, o acesso às informações, conhecimentos técnicos e científicos da sociedade nacional e demais sociedades indígenas e não índias.

Art. 79. A União apoiará técnica e financeiramente os sistemas de ensino no provimento da educação intercultural às comunidades indígenas, desenvolvendo programas integrados de ensino e pesquisa.

$\$ 1^{\circ}$ Os programas serão planejados com audiência das comunidades indígenas.

$\$ 2$ O Os programas a que se refere este artigo, incluídos nos Planos Nacionais de Educação, terão os seguintes objetivos:

I - fortalecer as práticas socioculturais e a língua materna de cada comunidade indígena;

II - manter programas de formação de pessoal especializado, destinado à educação escolar nas comunidades indígenas;

III - desenvolver currículos e programas específicos, neles incluindo os conteúdos culturais correspondentes às respectivas comunidades;

IV - elaborar e publicar sistematicamente material didático específico e diferenciado.

No bojo dos debates sobre os direitos constitucionais e particularmente os direitos formalmente constituídos, referentes à educação escolar indígena diferenciada, aflora um otimismo quanto às possibilidades da educação escolar como instrumento de fortalecimento e valorização dos povos indígenas. A partir da Constituição Federal de 1988 e da LDB desencadeou-se um amplo corpo legal regulamentando a educação escolar indígena diferenciada. A Resolução no 3 (CNECEB), de 10 de novembro de 1999, por exemplo, fixa as diretrizes para o funcionamento das escolas indígenas. ${ }^{16}$ Conforme estabelece a Resolução, as escolas indígenas deverão respeitar a realidade de cada povo, criando currículos que atendam a diversidade desses povos. O parágrafo único do $6^{\circ}$ artigo estabelece a garantia de os professores indígenas realizarem a sua formação em serviço. O documento define que a educação escolar indígena diferenciada deverá ocorrer em sistema de cooperação das três esferas 
governamentais (União, estados e municípios), e que os municípios deverão ofertar a educação escolar indígena se tiverem interesse e condições de ofertar.

Outro documento que formaliza a educação escolar indígena diferenciada estabelecendo os parâmetros de seu funcionamento é o Decreto 6.861/2009, que reafirma os compromissos dos documentos anteriormente apresentados, especialmente a Resolução no 3 de 1999, criando os territórios etnoeducacionais. $\mathrm{O}$ documento esclarece que

cada território etnoeducacional compreenderá, independentemente da divisão político-administrativa do País, as terras indígenas, mesmo que descontínuas, ocupadas por povos indígenas que mantêm relações intersocietárias caracterizadas por raízes sociais e históricas, relações políticas e econômicas, filiações linguísticas, valores e práticas culturais compartilhados. (artigo $5^{\circ}$, parágrafo único)

Paralelamente ao processo de formalização da educação escolar indígena diferenciada, ocorre um acirrado debate nacional sobre a temática nas academias e nos meios sociais, com a produção de uma extensa bibliografia sobre o tema e criação de órgãos públicos específicos para administrar essa modalidade de escola, tanto no nível nacional quanto no local, nos estados e municípios.

Analisando as possibilidades da educação escolar indígena, Ângelo ${ }^{17}$ defende que a melhor escola indígena é aquela pensada, elaborada e gerida pela própria comunidade, que respeite os interesses e a forma de organização de cada povo. Essa perspectiva confronta com o velho modelo das escolas indígenas que pretenderam 'civilizar', catequizar ou 'integrar' os indígenas à comunhão nacional, impondo normas e um currículo escolar desvinculado da realidade indígena.

Atualmente, a legislação que rege a educação escolar indígena no Brasil aparentemente se distanciou do ideal de 'integrar', 'assimilar' e catequizar. A retórica do Estado aponta para o respeito à diversidade desses povos, tendo a escola como o espaço para a valorização e o fortalecimento dos seus modos de organização social. No entanto, a realidade nem sempre está em sintonia com o que determina a legislação. A esse respeito, Meneses observa que

a educação indígena vive dilemas e conflitos entre a 'teoria' e a 'prática'. Por um lado, tem-se uma legislação ambiciosa e sedutora, que promete proteger e incen- 
tivar as diversas culturas indígenas, resgatando suas línguas, promovendo seus valores e admitindo suas diferenças e, por outro, há uma implementação precária das propostas diferenciadas, muito distantes do idealizado pelas leis e com grande dificuldade de se afastar do modelo nacional de educação.

Um dos aspectos questionáveis da real natureza 'diferenciada' dos projetos pedagógicos da educação indígena é a insistente ênfase na alfabetização dos povos indígenas. ${ }^{18}$

Alguns estudos têm chamado a atenção para as dificuldades e os limites da implantação da educação escolar indígena diferenciada. Dalmolin (2004), por exemplo, aponta o pouco empenho do poder público na questão, ao passo que Dias levanta a problemática da "introdução da escrita, enquanto nova forma de expressão" (1997, p.60) e os perigos de a tradição oral ser suplantada. A autora conclui: "A tradição oral é a única linguagem que não se pode saquear, roubar, repetir, plagiar, copiar...” (ibidem, p.60).

Dias da Silva (1997) apresenta como uma das maiores tensões no campo da educação escolar indígena diferenciada a utilização da escrita, em que estão em campos diferentes duas formas de linguagem: "a tradição cultural, onde a grande força é a oralidade, versus a nova forma de expressão e registro, a escrita" (ibidem, p.59). A autora afirma que um dos desafios dessa proposta educacional é conciliar as duas formas de linguagem, sem prejuízo para a tradição originalmente indígena, a oral. Outro aspecto colocado pela autora é o tema da interculturalidade, em que o diálogo entre os diferentes povos deve se dar numa situação de segurança, pois a "dialogicidade não se constrói enquanto posição de entreguismo ou retirada, nem é estabelecida entre vencidos e vencedores" (ibidem, p.61). Nesse sentido, talvez não seja possível uma educação escolar intercultural enquanto os povos indígenas estiverem em situação de vulnerabilidade em termos territoriais, por exemplo.

Sobre a possibilidade do diálogo intercultural na escola indígena, Repetto (2008) observa que:

Não adianta pensar em interculturalidade na educação se o sistema não cumpre suas obrigações com materiais para que o diálogo ocorra; isto significa investimento na formação de profissionais da educação, investimento em infraestrutura adequada aos interesses e realidade dos povos, não apenas impor escolas padronizadas e envio de merendas estragadas ou pouco valorizadas pelas culturas, e 
ainda materiais escolares homogeneizantes e fora da realidade, significa que chegue a merenda e que seja de qualidade, dentro do conceito de qualidade de cada povo e comunidade. ${ }^{19}$

O autor lembra que o diálogo intercultural não é simples e que a educação intercultural indígena não pode se pautar apenas em pressupostos conceituais e epistemológicos; mais que isso, serão necessárias ações políticas e investimentos financeiros efetivos, caso contrário a proposta se limitará ao campo do discurso.

Dalmolin $^{20}$ reconhece que apesar das dificuldades e do pouco empenho do poder público, a educação indígena diferenciada alcançou conquistas já visíveis, se comparada com a perspectiva da 'escola para os índios' que por séculos funcionou com a intenção de integrar os povos indígenas à comunhão nacional. No entanto, Luciano insiste em que a educação escolar indígena diferenciada parte da premissa de que é necessário superar o já falido modelo de educação integradora.

A educação escolar indígena diferenciada é um processo de incipiente implementação que depende da vontade política do poder público e da adoção de medidas concretas para a sua efetiva realização. Do ponto de vista das políticas curriculares, a proposta deve ser entendida somente como um instrumento que já faz parte da realidade escolar indígena desde a chegada dos portugueses ao Brasil, podendo tomar outros caminhos, com mais proximidade em relação à realidade dos povos indígenas, diferente do viés integracionista historicamente assumido pelo Estado. Certamente não será a escola quem ensinará o indígena a ser o que ele é; ela pode apenas colaborar, criando práticas curriculares que levem em conta as histórias e os modos de organização social próprios desses povos. A escola não será a redentora das tradições indígenas, e é improvável que ela abandone todos os ranços herdados da escola catequizadora e 'civilizadora'.

No Amapá, a proposta da educação escolar indígena diferenciada está em debate desde o final da década de 1980. A promulgação da Constituição Federal de 1988 transformou o Território Federal do Amapá em estado da Federação e, em 1991, a recém-criada Assembleia Legislativa daquele estado promulgou a Constituição estadual, estabelecendo no seu artigo 330, parágrafo terceiro: 
Art. 330. O Estado proporcionará às comunidades indígenas o ensino regular, na língua indígena original da comunidade e em português, devendo o órgão estadual da educação desenvolver programas de formação de professores indígenas bilíngues para o atendimento dessas comunidades.

O texto constitucional é bastante claro na formulação dos parâmetros da educação escolar indígena diferenciada voltada aos povos indígenas daquele estado.

Do ponto de vista do protagonismo indígena, lideranças e professores indígenas realizavam assembleias frequentes para debater sobre a educação escolar indígena diferenciada. Em 1995 ocorreu a criação da Associação dos Professores Indígenas do Oiapoque (Opimo), uma organização que se encontra fortalecida atualmente no Amapá.

$\mathrm{Na}$ aldeia Karipuna do Espírito Santo os debates aconteciam, tendo como articulador principal o Karipuna Fernando Forte, que em entrevista concedida em outubro de 2009 deu este depoimento:

Apesar do nosso distanciamento em relação aos centros urbanos, nós, povos indígenas do Oiapoque estamos muito organizados, estamos entre os índios mais bem articulados do Brasil. Desde o início das discussões sobre a educação diferenciada nós estamos acompanhando tudo, realizando encontros locais e viajando para os encontros nos outros estados e em Brasília. Queremos nossa escola forte e nossos filhos cada vez mais sabidos, sem deixar a cultura de lado.

Conforme demonstra Ricardo (1983), desde a década de 1980 o Conselho Indigenista Missionário (Cimi) vinha realizando experiências educacionais diferenciadas na escola da aldeia do Espírito Santo, expressando a necessidade de valorizar e fortalecer as tradições Karipuna, com a produção de materiais didáticos próximos à realidade local e a formação de professores indígenas para atuar nas escolas das aldeias.

Portanto, a escola da aldeia do Espírito Santo vem acompanhando os debates sobre a proposta da educação escolar indígena diferenciada desde o início da sua projeção, o que não significa nem de longe que a escola naquela aldeia esteja numa situação tranquila de implantação e execução da proposta diferenciada. 


\section{NOTAS}

${ }^{1}$ ARNAUD, Expedito. O índio e a expansão nacional. Belém: Cejup, 1989.

${ }^{2}$ VINCENT, Guy et al. Sobre a história e a teoria da forma escolar. Educação em Revista, Belo Horizonte, n.33, p.7-47, jun. 2001. p.37-38.

${ }^{3}$ CARVALHO, Marta M. C. A escola e a República e outros ensaios. Bragança Paulista (SP): Edusf, 2003. p.314.

${ }^{4}$ SCHWARTZMAN, Simon. (Org.). Estado Novo, um auto-retrato (Arquivo Gustavo Capanema). Brasília: Ed. Universidade de Brasília, 1982.

${ }^{5}$ RICARDO, Carlos A. Povos indígenas no Brasil. São Paulo: Cedi, 1983. (v.3, Amapá/Norte do Pará).

${ }^{6}$ RONDON, Candido M. S. Índios do Brasil das cabeceiras do rio Xingu, dos rios Araguaia e Oiapoque. Rio de Janeiro: Ministério da Agricultura, 1953. v.II, p.282.

${ }^{7}$ ASSIS, Eneida Correia de. Escola Indígena: uma frente ideológica? Dissertação (Mestrado) - PPGAS, UnB. Brasília, 1981.

${ }^{8}$ TASSINARI, Antonella Maria I. No bom da festa: o processo de construção cultural das famílias Karipuna do Amapá. São Paulo: Edusp, 2003. p.361.

${ }^{9}$ ARNAUD, Expedito. Os índios Palikur do rio Urucauá: tradição tribal e protestantismo. Belém: Museu Paraense Emílio Goeldi, 1984. (Publicação avulsa, 38).

${ }^{10}$ TASSINARI, A. M. I. Da civilização à tradição: os projetos de escola entre os índios do Uaçá. In: SILVA, Aracy Lopes; FERREIRA, Mariana K. Leal (Org.). Antropologia, História e educação: a questão indígena e a escola. São Paulo: Global, 2001.

${ }^{11}$ DIAS DA SILVA, Rosa H. Povos indígenas, Estado Nacional e relações de autonomia: o que a escola tem com isso? In: In: MATO GROSSO. Secretaria de Estado da Educação. Urucum, jenipapo e giz: a educação escolar indígena em debate. Cuiabá: Entrelinhas, 1997. p.66.

${ }^{12}$ LUCIANO, Gersem dos Santos. O índio brasileiro: o que você precisa saber sobre os povos indígenas no Brasil de hoje. Brasília: MEC/Secad; Museu Nacional, 2006.

${ }^{13}$ MINDLIN, Betty. O aprendiz de origens e novidades: o professor indígena, uma experiência da escola diferenciada. Estudos Avançados, São Paulo, v.8, n.20, jan.-abr. 1994. p.235.

${ }^{14}$ BRASIL. Ministério da Educação e do Desporto. Secretaria de Educação Fundamental. Referencial curricular nacional para as escolas indígenas. Brasília, 1998.

${ }^{15}$ BRASIL. Lei de Diretrizes e Bases Educação Brasileira. Brasília: Senado Federal, 1996.

${ }^{16}$ BRASIL. Resolução 03/99/CNE: Fixa Diretrizes Nacionais para o funcionamento das escolas indígenas. Brasília: MEC, 1999.

${ }^{17}$ ÂNGELO, Francisca Novantino P. de. A educação e a diversidade cultural. Cadernos de 
educação escolar indígena (3o grau indígena), Barra do Bugres: Unemat, n.1, v.1, p.34-40, 2002.

${ }^{18}$ MENESES, Gustavo H. Conhecimento e poder: dilemas e contradições na educação escolar indígena. Revista de Estudos e Pesquisa, Brasília: Funai/CGEP/CGDTI, v.2, n.2, dez. 2005. p.128.

${ }^{19}$ REPETTO, Maxim. A formalização das propostas pedagógicas das escolas indígenas e a construção de cidadanias diferenciadas. Cadernos de educação escolar indígena, Barra dos Bugres: Unemat, v.6, n.1, 2008. p.45.

${ }^{20}$ DALMOLIN, Gilberto Francisco. O papel da escola entre os povos indígenas: de instrumento de exclusão a recurso para emancipação sociocultural. Rio Branco: Edufac, 2004.

Artigo recebido em 20 de junho de 2012. Aprovado em 1ํo de setembro de 2012. 